\title{
Mediating workplace situational pressures: The role of artefacts in promoting effective interprofessional work and learning
}

\author{
A. Teodorczuk \& S. Billett ${ }^{2}$
}

\begin{abstract}
Introduction: This theoretical paper is a scenario-based account of interprofessional healthcare work that highlights tensions between desired and actual practice behaviour in clinical settings.

Case Study: In this account, against his best clinical judgment and because of situational ward pressures, a junior doctor prescribes antipsychotic medication for a high-risk confused, frail, elderly patient. A healthcare assistant, who possesses key patient-specific information, holds back on sharing this information because of similar pressures.

Analysis: Sociocultural analysis of this account identifies three epistemological factors constraining an individual's discretion and behaviour. First, situated team collective practice overrides individual knowledge. Secondly, collective practice, though held strongly by core members of clinical teams, may in fact be erroneous, and fail to support new learning about and through practice, to the detriment of patient care. Thirdly, situated practices of the ward community may marginalise some team members and inhibit their contributions to patient safety.

Conclusions: To redress such constraints, we propose the development of, and engagement with, artefacts or tools that shape inclusive practice and assist improvements in practice. Such an approach can lead to productive learning through practice in interprofessional healthcare teams. To elaborate the case, the illustrative example of the Delirium Early Monitoring System (DEMS) is used. This artefact can be effective in socioculturally mediating unhelpful situational pressures that impact on clinical teams' management of delirium, by including and legitimising a range of professional
\end{abstract}

1 School of Medicine, Griffith University, Australia

2 School of Education and Professional Studies, Griffith University, Australia

Correspondence

A/Professor Andrew Teodorczuk

School of Medicine

Griffith University

Gold Coast Campus

Queensland 4222

Australia

Tel: +61 756780891

Email: A.Teodorczuk@griffith.edu.au 
voices. This mediation can also include voices that are external to the immediate clinical situation, which can inform interprofessional care, promote interdependence and foster patient-centred working communities of healthcare practice.

Keywords: work-based learning; sociocultural analysis; interprofessional care; delirium.

\section{Introduction}

Through reference to an account of a clinical incident, this paper explores how to address some of the assumptions and tensions that are at play in interprofessional healthcare work in the context of delirium care. Following the analysis of this incident, we advance an explanatory model to reshape practice and to support new learning through the use of a clinical tool ("artefact"). Crucially, such a tool can be used to mediate interprofessional work, working relations and learning. To explain this approach, we use the Delirium Early Monitoring System (DEMS) tool to illustrate how the development and use of such artefacts can encourage helpful contributions, diminish tensions in clinical decision making and promote interprofessional learning. This case draws attention to the central role that can be played by such artefacts in: i) redressing ward tensions, ii) legitimising contributions from marginalised staff and iii) improving interprofessional holistic care processes that can be applied in clinical practice.

The paper's core premise is a product of interviews with healthcare professionals about delirium and dementia care from an earlier study (Teodorczuk, 2011) and is based on an account of practices observed in a busy hospital ward. Though concerned with the care of a patient who is delirious (acutely confused), the case has relevance for all care staff who work collaboratively and seek to improve interprofessional care.

\section{Case study}

\section{Scenario-based account of situated practice}

Mark is a new junior doctor commencing a 6-month rotation on a surgical ward in a busy district general hospital. He has attended lunchtime teaching rounds and has learned about falls in the elderly. Consequently, he is aware of the increased association between dementia and falls and, now, knows that when prescribing for this patient subgroup, it is important to "start low and go slow". He recalls from his studies that sedative medications (such as antipsychotics) should be avoided.

One evening, whilst on call, Mark is paged to attend an orthopaedic ward, urgently, to see $\mathrm{Mr}$ Stevens, an 85-year-old man who is 2 days post-operative, having had knee surgery. Mr Stevens was formerly manager of a successful manufacturing business, where he was a well-respected boss and managed a "tight ship", overseeing up to 100 employees. Medically, Mr Stevens has a background of early Alzheimer's disease (dementia) and has been attending a memory clinic. His knee replacement operation was relatively successful, although he is still experiencing pain in his knee. 
Mark has been called to the ward because, in the last 24 hours, Mr Stevens has become increasingly agitated and confused. $\mathrm{Mr}$ Stevens has been shouting at ward staff and demanding that they stop "hitting him". He is particularly angry because he believes a nurse has struck his knee with a stick and, on one occasion, he threw a vase at a staff member. On arriving, Mark finds the nursing staff sitting at their workstation with a drug chart to be filled out for $\mathrm{Mr}$ Stevens. They are demanding immediate prescription of high-dose haloperidol (an antipsychotic) to manage the situation, as they claim there are no other alternatives.

Mark explains his concerns about the heightened risk of falls but is told that "this is how patients are managed on the ward". Reluctantly, he prescribes the medication yet remains anxious about the possibility of a fall. Later that evening, he speaks with a healthcare assistant, Molly, about these concerns. She is familiar with Mr Stevens and, having spoken to his family, speculates that some of his behaviour arises from an altercation with a staff member many years ago, when he was kicked in the knee. She reports that his family says that he has very high personal standards and can be quite demanding.

Mark completes his shift feeling disappointed with his actions, regretting his prescribing action and concerned that $\mathrm{Mr}$ Stevens may consequently have a fall. Molly goes home equally frustrated that she was unable to advise and intervene. In this way, two healthcare practitioners conclude that their professional practice has been compromised by the situational pressure of preferred ward practices.

\section{Analysis}

\section{Initial theoretical appraisals of this incident}

Individuals' clinical practice is influenced by and situated within the particular sociocultural environments where they work (Teodorczuk, Mukaetova-Ladinska, Corbett, \& Welfare, 2015). Healthcare professionals' actions at work may be quite different from those that they would ordinarily choose outside that environment (Chia \& MacKay, 2007). This case highlights a dissonance between the situated collective team practice enacted in a particular work community (Gherardi, 2009) and not only the knowledge that Mark had acquired from recent clinical teaching sessions about the management of patients with delirium but also Molly's knowledge of the patient.

Two workers, a healthcare assistant and a junior doctor, suffered relatively constrained agency over their actions because the situated practices within the particular healthcare practice community did not allow optimal healthcare actions on the ward (Milne, Greenfield, \& Braithwaite, 2015; Reeves et al., 2009). By situated practices, we mean the localised norms of practice that generate behaviours shaping how work is to be conducted in a particular circumstance.

Both of these healthcare professionals were constrained by the strong situated practice within the work community, which inhibited the potential of interprofessional care being achieved as a result of inclusive and fully-informed collaborative decisionmaking. The understandings of both these healthcare professionals were at variance with practices that were situationally sanctioned. Hence, their professional contributions 
were, respectively, rebuffed and ignored. In the junior doctor's case, a tension arose as he negotiated unsuccessfully with the situated norms, forms and practice of the ward. Mark did not intend to practise ineffectively, but he concluded that this is what had occurred as he prescribed against his best clinical judgment.

Unfortunately, this phenomenon, which is based on a detailed explorative study (Teodorczuk, 2011), appears to be common and will be familiar to many in clinical practice (Lewis \& Tully, 2009). The claim that health professionals learn how to work effectively through benign and supportive social processes (Lave \& Wenger, 1991) seems to be erroneous.

Rather, throughout clinical workplaces, health professionals may become members of practice communities that have strong norms and practices with which they are expected to conform and, in so doing, potentially to engage in unsafe or ineffective practices (Fox \& Reeves, 2015; Gherardi, 2009). Such practices can lead to healthcare scandals (Francis, 2013). In the UK, for instance, the negative culture on a midwifery ward in Furness, Cumbria, led to unsafe behaviour and increased childbirth complications and deaths (Donnelly, 2015). Crucially, such practice communities may resist change, even though their healthcare practices may compromise patient safety, and negative outcomes may eventuate.

The challenge is to modify inappropriate aspects of situated-practice and learning contexts by equipping new doctors and other healthcare professionals to negotiate their contributions effectively, and thus to change the erroneous practices being enacted in their healthcare setting (Regehr, 2010). Because marginalised healthcare professionals may feel alone and powerless to act within these practice settings, personal mediation may be insufficient. Evidence-based tools, or artefacts, can be used to make practice more effective and to promote safer ward actions. Such artefacts (e.g., the Modified Early Warning System, MEWS) have been used successfully in other settings in monitoring vital signs (Subbe, Kruger, Rutherford, \& Gemmel, 2001), and in this paper, one such artefact is applied to the case of the delirious patient.

\section{Understanding the case}

Three key issues identified in this case are: situated pressure overriding effective practice, situated practice being misaligned with contemporary therapeutic guidelines and interprofessional hierarchies inhibiting effective change and learning.

\section{Situational practices overriding effective practice}

In the clinical education literature on dementia and delirium care, a "knowing-doing gap" has been identified (Greysen, 2015; Teodorczuk, Welfare, Corbett, \& MukaetovaLadinska, 2009). The assumed focus for clinical educators' teaching is to help learners to close the gap between what is currently known and what can be applied successfully in practice (Tabet \& Howard, 2006; Teodorczuk et al., 2009; Yanamadala, Wieland, \& Heflin, 2013). A prevailing assumption in clinical practice is that there is a clear linear relationship between the acquisition of knowledge learnt outside clinical practice and its application in clinical settings (Swanwick, 2005). However, given the complexity 
of ward environments, and Mark and Molly's lack of agency over their actions, we propose that "closing the knowing-doing gap" must also focus on overcoming the situated pressure of care settings (Teodorczuk et al., 2015) in ways that are not wholly reliant on personal mediation. We contend that all relevant voices must be heard and their involvement legitimised.

Situation-specific norms may be privileged in particular circumstances of practice. From the incident presented above, the norms for practice within the ward team were deployed to override the junior doctor's knowledge of best practice and the insights that can be provided by the healthcare assistant. The practice of the community (Gherardi, 2009) drove decision making and behaviours in the ward, and led to tensions and the disempowerment experienced by the junior doctor and the healthcare assistant.

\section{Situated knowledge and practices misaligned with learning through practice}

A second issue is to what extent team-situated norms of practice are aligned to the ageing population that the healthcare setting serves. That is, there is a need to maintain a focus on the key stakeholders, the patients, rather than privileging the norms and practices of the ward's community, and potentially outdated normative practices associated with dementia and delirium care.

One consequence of this misalignment is that staff will find it challenging to implement effective care for the complex needs of older patients with dementia and delirium, for instance, and will, instead, enact outdated models of care (Clissett, Porock, Harwood, \& Gladman, 2014; Marshall, 1999, 2001; Moore et al., 2015). Worse still, as in the incident above, newcomers with current and pertinent knowledge may be marginalised and, thus, rendered unable to negotiate to modify the ward's pervasive situated-normative practices. Ultimately, such resistance to change may lead to poor or even dangerous clinical practice.

As noted, learning is intertwined with practice (Lave \& Wenger, 1991), and constraints of traditional practices can potentially restrict efforts to adapt and reshape practice to respond to changing hospital populations. The lack of a means to acquire fresh perspectives and practices may widen the gap between contemporary best practice and what is tolerated within the practice community, at a cost to its patients. Hence, as knowledge of optimal care develops, methods must be developed to advance and enhance situated practice so that it remains current in meeting changing patient requirements.

\section{Interprofessional hierarchies inhibit knowledge-sharing activities amongst staff}

A third consideration of this incident is the impact of ward hierarchies on interprofessional work in a way that inhibits knowledge about patients being shared (Reeves et al., 2009). The complexity of dementia and delirium care means that, in managing patients with confusion, knowledge is required about each patient rather than simply about their disease (Teodorczuk et al., 2015). Conceptually, "learning about the patient" is now a central component of dementia and delirium care. 
In the account above, crucial knowledge about the patient would have included the fact that, pre-morbidly, $\mathrm{Mr}$ Stevens was exacting by nature and had previously sustained a work-related injury by a violent employee. This knowledge could have been used to understand how he had misinterpreted the wound from the operation as an injury incurred in a previous assault. Such a perceived insult could account for his hostile behaviour towards the nursing staff. The healthcare assistant possessed this level of knowledge but was unable to share it with other staff because of the ward hierarchies. No opportunities for engagement existed for her to share this knowledge and to influence clinical decision making.

Consequently, she felt disempowered in that, despite having relevant knowledge, she was unable to use it effectively. This disempowerment is consistent with previous work describing how healthcare assistants, positioned on the margins of clinical teams, lack the means to contribute to patient care in interprofessional working (Lloyd, Schneider, Scales, Bailey, \& Jones, 2011).

\section{Developing innovative approaches to reshape practice and learning}

Recognising that practice and learning are intertwined, Mark has learnt to act against what he believed to be appropriate care. The learning here arose not from teaching but through mimetic processes that comprise personally-mediated learning (Billett, 2014). That is, observation, imitation and, in this case, inappropriate action arise through how individuals come to construe and construct what they experience. Important learning, therefore, arises through highly-contextualised practice (Lakoff \& Johnson, 1999) as well as structured teaching experiences.

Achieving informed working and learning in such circumstances necessitates finding ways to promote relevant learning and effective interprofessional care through wider engagement and informed consideration of practice. Through his failed negotiations, Mark learned that the potency of situated practice over clinical teaching sessions necessitated the development of ways to circumvent situated pressures to promote effective, relevant and safe patient care.

At present, among some clinical education providers, there may be a linear view that increasing knowledge through teaching activities will lead to subsequent change in practice behaviour. For these providers, the emphasis is on knowledge first, and an assumption that changes to practice will then follow. Through analysis of this case, we propose that there is a need to flip this perspective and provide well-ordered practicebased learning, but in ways that simulate situated pressures. Educators who seek to improve practice and learning might be encouraged first to examine what practitioners are doing, and then, how this informs the education or change process. Rather than focusing on closing the knowing-doing gap, and the well-documented challenges associated with this strategy, there is a need to focus on the doing-knowing gap. By this, we mean that there should be a focus on what is learnt through practice first and foremost. Subsequently, there should be reshaping practice to promote the creation of relevant knowledge. 
Hence, by unpacking the complexity of practice behaviour and associated learning, it is possible for educators to focus on the task of reshaping work activities as the core mechanism to improve knowledge, skills and attitudes in clinical settings. This requires the discovery of ways in which the pressures of situated practice can be challenged and the development of processes to promote more effective interprofessional working.

\section{Mediational role of artefacts in restructuring practice}

Artefacts can be a useful tool to mediate interprofessional interactions and reshape normative practices. An artefact is a tool that can mediate culturally- and situationallydependent practice by influencing situational factors. The airline pilot's check list is a useful example-the items in the list have to be worked through in sequence, and a first officer cannot be overruled by the captain, because the required sequence of checks must be undertaken.

As a worked example, we outline how such an artefact, the Delirium Early Monitoring System (DEMS) (Rippon et al., 2016) (Figure 1), can be used to shape more effective learning and to modify the situated pressures and promote the inclusion of different perspectives in promoting effective interdisciplinary practice and learning in relation to patients with delirium. DEMS is based on an understanding of maladaptive delirium practice and provides an evidence-based approach to improve learning in the workplace.

\section{Using DEMS in practice}

As depicted in Figure 1, the artefact DEMS is a scoring system that non-medical staff undertake regularly to identify and manage delirium effectively. DEMS is completed twice a day, and specific actions result from the delirium score that staff assign to a patient (e.g., a DEMS score variation of $\geq 2$ from the previous observation results in the score being recorded in the patient's electronic medical notes and reported to the shift coordinator for medical review within 4 hours). The detail of how DEMS can be introduced into the workplace and the scoring system embedded in care processes have been described elsewhere (Rippon et al., 2016). In essence, DEMS is completed in a similar manner to monitoring changes in blood pressure. Further delirium (DEMS) scores can be routinely included in clinical meetings and decision making to monitor delirium as an additional vital sign.

It is important to note that DEMS links screening to action. Though adapted (with permission) from the validated Delirium Observation Screening Scale (Schuurmans, Shortridge-Baggett, \& Duursma, 2003), it is neither a screening tool nor a guideline. Its role is to inform new and/or more inclusive practice behaviours and to help staff to learn about delirium and to make more informed and inclusive decisions about patient care. The reverse side of the form shown in Figure 1 provides information about the actions that should arise from the assignment of a score to a patient, together with information about delirium.

From the case study reported earlier, staff such as Molly, who have relevant knowledge about the confused older patient, and a junior doctor with current medical knowledge now have a mechanism through which they can contribute to care in a clinically- 


\section{MEDIATING WORKPLACE SITUATIONAL PRESSURES}

Delirium Early Monitoring System (DEMS)

\begin{tabular}{|c|c|c|c|c|c|c|c|c|c|}
\hline \multirow{2}{*}{\multicolumn{2}{|c|}{$\begin{array}{l}\text { Name: } \\
\text { Patient No: }\end{array}$}} & & & & & & & & \\
\hline & & \multicolumn{2}{|c|}{ Date: } & \multicolumn{2}{|c|}{ Date: } & \multicolumn{2}{|c|}{ Date: } & \multicolumn{2}{|c|}{ Date: } \\
\hline & & AM & PM & AM & PM & AM & PM & AM & PM \\
\hline 1 & Easily distracted by stimuli & & & & & & & & \\
\hline 2 & Does not maintain attention to conversation & & & & & & & & \\
\hline 3 & Does not finish when asking a question or providing an answer & & & & & & & & \\
\hline 4 & Provides irrelevant answers & & & & & & & & \\
\hline 5 & Reacts slowly to instructions & & & & & & & & \\
\hline 6 & Disoriented to place & & & & & & & & \\
\hline 7 & Does not know which part of the day it is & & & & & & & & \\
\hline 8 & Unable to remember a recent event & & & & & & & & \\
\hline 9 & Is agitated, disordered and restless & & & & & & & & \\
\hline 10 & Can become suddenly emotional & & & & & & & & \\
\hline 11 & Evidence of hallucinations & & & & & & & & \\
\hline 12 & Attempts to pull off name tag, IV tubes, feeding tubes or catheter & & & & & & & & \\
\hline 13 & Dozes off during conversations or actions & & & & & & & & \\
\hline & DEMS Score (total) & & & & & & & & \\
\hline
\end{tabular}

Allocate 1 mark for the presence of an observation and sum the total marks to obtain the DEMS score for the shift (am or pm). Then proceed to actions (side 2)

\section{Delirium Early Monitoring System (DEMS)}

\section{ACTIONS}

Increase in DEMS score of 3 or more from previous assessment: notify shift coordinator to schedule a medical assessment within 4 hours

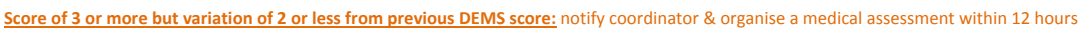
Score less than 3: No course of action. Continue monitoring

ESSENTIAL FACTS
preventable and treatable and therefore should be
monitored closely, similar to how we monitor blood
pressure on the ward.
- Delirium is characterised by distractibility,
disorganised thinking and changes in the level of
consciousness which fluctuate over time.
- There may be reversal of sleep-wake cycle
and hallucinations.
- Preventing delirium is important to prevent further
progression of dementia.
- Delirium is a medical emergency and hence should
be acted on soon.

\section{MANAGEMENT OF DELIRIUM}

Management involves recognising common causes and ACTING ON THEM!

Has your patient been troubled by:

- Pain $\rightarrow$ ask, look for non-verbal clues, trial of PRN analgesia, Dr review

- Infection $\rightarrow$ MSU, sputum sample, blood tests, Dr review

- Nutrition $\rightarrow$ check calorific intake, is there an apparent loss of appetite?

- Constipation $\rightarrow$ look at bowel chart, regular toileting, offer laxative if appropriate

- Hydration $\rightarrow$ look at fluid balance chart, offer drinks regularly

- Medication $\rightarrow$ Dr review, have there been any recent changes made?

- Environment $\rightarrow$ change of scene, remove to a quiet place, calming measures

Figure 1. The Delirium Early Monitoring System (DEMS), an artefact designed to reshape practice so that healthcare assistants can contribute to clinical decision-making processes and, thus, learn about delirium through practice. 
informed way. DEMS provides a point of entry for those who, because they spend more time interacting with patients and carers, have additional and non-clinical knowledge of the patient. In this instance, DEMS is intended to be completed by healthcare assistants, and it can also empower these workers to engage productively with other healthcare professionals. Through having completed the patient's DEMS, healthcare assistants and junior clinicians will be empowered by being brought into, and making contributions to, clinical conversations about patients, which will enhance all team members' understanding of delirium.

In addition to promoting concepts of worker (learner) interdependence (Billett, 2006), DEMS may also, at an earlier stage, introduce discussion, new language and effective clinical practice to meet the needs of patients with delirium and dementia. This could help to avert a culture whereby quick pharmacological fixes are used to address ward crises.

A limitation of DEMS is the fact that it may become buried under a sea of other forms and managerial requirements, and staff may not see its value and will choose to complete it later, with little thought. However, from our pilot work (Rippon et al., 2016), DEMS can be integrated successfully into daily practice, although high-level organisational support and accompanying training is essential.

In summary, artefacts such as DEMS can support productive learning through mediating in the process of decision making and by facilitating the engagement of staff whose voices are not always considered in hierarchical workplaces, or where particular situated pressure restricts access to clinical knowledge that can inform patient care. So, just as the introduction of the surgical checklist has reinforced the importance of patient safety within the operating theatre (Haynes et al., 2009) and invites all to contribute, similarly DEMS can act to align practice and learning to a new patient demographic in relation to delirium care.

\section{Conclusions}

An evidence-based approach drawing on an authentic clinical incident in the healthcare practice of dementia and delirium has been used to illustrate the importance of finding ways of modifying situated-normative practices to promote engagement and inclusiveness within interprofessional work. It suggests how healthcare professionals can be included in decision making and can mitigate strong normative practices that may cause resistance to change, particularly where and when such change is warranted. The impervious and perilous nature of such unquestioned normative practices is well acknowledged. Therefore, it is necessary to develop and to implement tools such as DEMS to assist all healthcare workers to contribute their knowledge to such deliberations and decision making.

We describe how the use of a textual artefact (i.e., DEMS) can mediate situational practices and can encourage and legitimise the full participation of members of interprofessional healthcare teams. In epistemological terms, practice and knowledge are dynamic, contextual and situated. Knowledge changes, and the knowledge to be 
learnt for work similarly must be developed, structured and supported as a duality between individuals' participation and learning and the remaking of clinical practice (Billett, 2006). Artefacts such as DEMS and other tools can allow the reshaping and promotion of more inclusive practice and, thereby, improve interprofessional care and assist in the complex tasks of caring for the older confused patients who are increasingly populating hospital wards.

The discussion and proposed approach has pertinence for caring for older confused patients. However, its reach may extend further and be of interest to all those who work interprofessionally to improve healthcare practice. The ability of new perspectives and additional advice to be included in the decision-making process can assist in reshaping situated collaborative practice that otherwise might inhibit these inputs and changes. In similar ways, other kinds of practitioners might find what is proposed here to be relevant to their efforts towards learning and the effective reshaping of interprofessional practice.

\section{Acknowledgement}

We would like to thank A/Professor Laurie Grealish for critically reviewing the paper in advance of submitting. We would also like to thank the reviewers for their helpful comments, which have significantly improved the paper.

\section{References}

Billett, S. (2006). Relational interdependence between social and individual agency in work and working life. Mind, Culture and Activity, 13, 53-69.

Billett, S. (2014). Mimesis: Learning through everyday activities and interactions at work. Human Resource Development Review, 13(4), 462-482.

Chia, R., \& MacKay, B. (2007). Post-processual challenges for the emerging strategyas-practice perspective: Discovering strategy in the logic of practice. Human Relations, 60(1), 217-242.

Clissett, P., Porock, D., Harwood, R. H., \& Gladman, J. R. (2014). The responses of healthcare professionals to the admission of people with cognitive impairment to acute hospital settings: An observational and interview study. Journal of Clinical Nursing, 23(13-14), 1820-1829. doi:10.1111/jocn.12342

Donnelly, L. (2015, 17 March). National probe into maternity care ordered after "lethal" mix of failings found. The Telegraph. Retrieved from http://www.telegraph. co.uk/news/health/news/11448226/National-probe-into-maternity-care-orderedafter-lethal-mix-of-failings-found.html

Fox, A., \& Reeves, S. (2015). Interprofessional collaborative patient-centred care: A critical exploration of two related discourses. Journal of Interprofessional Care, 29(2), 113-118. doi:10.3109/13561820.2014.954284

Francis, R. (2013). Report of the Mid Staffordshire NHS Foundation Trust public inquiry. Retrieved from https://www.gov.uk/government/publications/report-ofthe-mid-staffordshire-nhs-foundation-trust-public-inquiry 
Gherardi, S. (2009). Community of pratice or practices of a community? In S. J. Armstrong \& C. V. Fukami (Eds.), The SAGE handbook of management learning, education and development (pp. 514-530). London, England: Sage. doi: $10.4135 / 9780857021038$

Greysen, S. R. (2015). Delirium and the "know-do" gap in acute care for elders. JAMA Internal Medicine, 175(4), 521-522. doi:10.1001/ jamainternmed.2014.7786

Haynes, A. B., Weiser, T. G., Berry, W. R., Lipsitz, S. R., Breizat, A. H., Dellinger, E. P., ... Gawande, A. A. (for the Safe Surgery Saves Lives Study Group). (2009). A surgical safety checklist to reduce morbidity and mortality in a global population. New England Journal of Medicine, 360(5), 491-499. doi:10.1056/ NEJMsa0810119

Lakoff, G., \& Johnson, M. (1999). Philosophy in the flesh: The embodied mind and its challenge to western thought. New York, NY: Basic Books.

Lave, J., \& Wenger, E. (1991). Situated learning: Legitimate peripheral participation. Cambridge, UK: Cambridge University Press.

Lewis, P. J., \& Tully, M. P. (2009). Uncomfortable prescribing decisions in hospitals: The impact of teamwork. Journal of the Royal Society of Medicine, 102(11), 481488. doi: 10.1258/jrsm.2009.090150

Lloyd, V., Schneider, J., Scales, K., Bailey, S., \& Jones, R. (2011). Ingroup identity as an obstacle to effective multiprofessional and interprofessional teamwork: Findings from an ethnographic study of healthcare assistants in dementia care. Journal of Interprofessional Care, 25(5), 345-351. doi:10.3109/13561820.2011.567381

Marshall, M. (1999). "They should not really be here": People with dementia in the acute sector. Age and Ageing, 28(Suppl. 2), 9-11.

Marshall, M. (2001). The challenge of looking after people with dementia. BMJ, 323(7310), 410-411.

Milne, J., Greenfield, D., \& Braithwaite, J. (2015). An ethnographic investigation of junior doctors' capacities to practice interprofessionally in three teaching hospitals. Journal of Interprofessional Care, 29(4), 347-353. doi:10.3109/135618 20.2015.1004039

Moore, A., Patterson, C., Nair, K., Oliver, D., Brown, A., Keating, P., \& Riva, J. J. (2015). Minding the gap: Prioritization of care issues among nurse practitioners, family physicians and geriatricians when caring for the elderly. Journal of Interprofessional Care, 29(4), 401-403. doi:10.3109/13561820.2014.966352

Reeves, S., Rice, K., Conn, L. G., Miller, K. L., Kenaszchuk, C., \& Zwarenstein, M. (2009). Interprofessional interaction, negotiation and non-negotiation on general internal medicine wards. Journal of Interprofessional Care, 23(6), 633-645. doi: $10.3109 / 13561820902886295$

Regehr, G. (2010). It's NOT rocket science: Rethinking our metaphors for research in health professions education. Medical Education, 44(1), 31-39. doi:10.1111/ j.1365-2923.2009.03418.x 
Rippon, D., Milisen, K., Detroyer, E., Mukaetova-Ladinska, E., Harrison, B., Schuurmans, M., ... Teodorczuk, A. (2016). Evaluation of the delirium early monitoring system (DEMS). International Psychogeriatics, 28(11), 1879-1887. doi:10.1017/s1041610216000983

Schuurmans, M. J., Shortridge-Baggett, L. M., \& Duursma, S. A. (2003). The Delirium Observation Screening Scale: A screening instrument for delirium. Research and Theory for Nursing Practice, 17(1), 31-50.

Subbe, C. P., Kruger, M., Rutherford, P., \& Gemmel, L. (2001). Validation of a modified early warning score in medical admissions. QJM, 94(10), 521-526.

Swanwick, T. (2005). Informal learning in postgraduate medical education: From cognitivism to "culturism". Medical Education, 39(8), 859-865.

Tabet, N., \& Howard, R. (2006). Prevention, diagnosis and treatment of delirium: Staff educational approaches. Expert Review of Neurotherapeutics, 6(5), 741-751.

Teodorczuk, A. (2011). Developing educational approaches for Liaison Old Age Psychiatry teams: A grounded theory study of the learning needs of hospital staff in relation to managing the confused older patient. Unpublished doctoral disseration, Newcastle University-Newcastle upon Tyne.

Teodorczuk, A., Mukaetova-Ladinska, E., Corbett, S., \& Welfare, M. (2015).

Deconstructing dementia and delirium hospital practice: Using cultural historical activity theory to inform education approaches. Advances in Health Science Education: Theory and Practice, 20(3), 745-764. doi:10.1007/s10459-014-9562-0

Teodorczuk, A., Welfare, M., Corbett, S., \& Mukaetova-Ladinska, E. (2009). Education, hospital staff and the confused older patient. Age and Ageing, 38, 252-253.

Yanamadala, M., Wieland, D., \& Heflin, M. T. (2013). Educational interventions to improve recognition of delirium: A systematic review. Journal of American Geriatrics Society, 61(11), 1983-1993. 